\section{Implant symposium set for Vegas}

The first global Keystone PALTOP implant symposium will be held in Las Vegas on 2-4 April 2020.

The symposium will help keep you current on the latest trends in implant dentistry, learn about science supporting long-term aesthetics, immediacy, guided digital workflows and prosthetic success. With an exemplary faculty drawn from all disciplines of dentistry combined with hands-on learning opportunities, the entire dental team will gain insights and knowledge to best meet their patients' needs and expectations - and have fun at the same time!

Attendance is $\$ 795$ with three nights at the Aria Resort Hotel in Las Vegas from $\$ 765$. Clinicians can register and stay for free when purchasing only 35 Keystone PALTOP implants from Ariston Dental UK.

Ariston Dental UK offers a wide range of products including dental implants, bone grafts, surgical instruments and specialised devices.

For further information email info@ ariston-dental.co.uk.

www.ariston-dental.co.uk

\section{For complex TMJ cases}

TMJ disorders can lead to an array of problems for patients. In severe cases where TMJ replacement is required, it's important that surgeons use trusted products. TMJ Concepts offers a comprehensive process for the design and fabrication of each fully customised TMJ reconstructive prosthesis. It allows the surgeon to sign off on the design at every step, ensuring accuracy and effectiveness of the device first time. This encourages excellent adaptation of the prosthesis, leading to the desired improvement in function and reduced pain.

If previous attempts to treat a patient's TMJ disorders have failed and surgery is now indicated, TMJ Concepts offers a trusted solution. For more information from Incito Medtech, call 07468420496 or email Karen.Joy@incitomedtech.co.uk or visit http://incitomedtech.co.uk.

\title{
A complete prophylaxis solution
}

When it comes to prophylaxis, W\&H understands that there is no one-size-fits-all approach. That's why W\&H offers a complete prophylaxis solution manufactured with the patient and practitioner in mind.

While the Proxeo Twist Cordless handpiece provides clinicians the flexibility to polish entirely without restrictions, the Proxeo Aura air polishing system facilitates thorough and efficient removal of soft deposits and stains - whether for prophylaxis or periodontal treatment.

In addition, Proxeo Ultra piezo scalers have been developed in collaboration with experts from the field. Graz University of Technology has confirmed that all $\mathrm{W} \& \mathrm{H}$ piezo scalers can be used to safely treat patients with pacemakers.

Contact W\&H to discover the Proxeo range of prophylaxis products today.

To find out more visit www. wh.com/en_uk, call 01727874990 or email office.uk@wh.com.

\section{Get involved with dental implants}

You don't need to commit to full dental implant training to get involved with the implantology field. Ten Dental+Facial offers a solution with its dedicated Implant Restoration Course (IRC) - an innovative modular programme taught over the course of a year.

Led by experienced implantologists, Dr Nikhil Sisodia and Dr Martin Wanendeya, the IRC covers the theory and practice of restoring implants - from initial diagnosis and treatment planning, to the application of the final restoration. This provides the ideal solution for clinicians looking to offer implant treatment, without having to undertake comprehensive implant surgical training.

Call Ten Dental+Facial for IRC course dates and to book your place.

For more information about Ten Dental+Facial and the Implant Restoration Course (IRC), email: office@tendental.com or call 02076227610.

\section{Save yourself the headache}

Are you fed up of having to stop midtreatment to clean and reposition your dental mirror? Nuview can save you from this headache with the Yirro-plus self-cleaning dental mirror system. It combines innovative air flow technology with an ultra-reflective coating to keep the mirror free from grease and other contaminants.

No matter whether you are drilling or performing prophylaxis treatment, Yirroplus ensures clear vision without the need to interrupt your workflow. This enables you to work more efficiently in order to save valuable time in practice.
To order your own Yirro-plus COMFORT or PREMIUM start set, get in touch with Nuview today.

For more information please call Nuview on 01453 872266, email info@ nuview-ltd.com, or visit www.nuview.co.

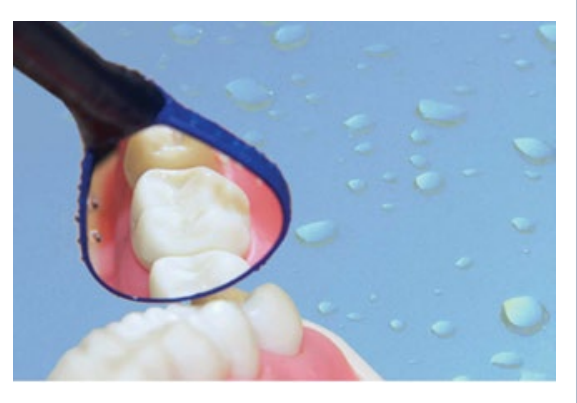

